\title{
State and Regional Prevalence of Diagnosed Multiple Chronic Conditions Among Adults Aged $\geq 18$ Years — United States, 2014
}

\author{
Brian W. Ward, $\mathrm{PhD}^{1}$; Lindsey I. Black, $\mathrm{MPH}^{1}$
}

The prevalence and care management of multiple (two or more) chronic conditions (MCC) are important public health concerns (1). Approximately $25 \%$ of U.S. adults have diagnoses of MCC (2). Care management of MCC presents a challenge to both patients and providers because of the substantial costs associated with treating more than one condition and the traditional care strategies that focus on single conditions as opposed to enhanced care coordination (3,4). Maintaining surveillance, targeting service delivery, and projecting resources are all important to meet this challenge, and these actions can be informed by identifying state and other regional variations in MCC prevalence (5,6). Data from the 2014 National Health Interview Survey (NHIS) were used to estimate prevalence of MCC (defined as two or more of 10 diagnosed chronic conditions) for each U.S. state and region by age and sex. Significant state and regional variation in MCC prevalence was found, with state-level estimates ranging from $19.0 \%$ in Colorado to $38.2 \%$ in Kentucky. MCC prevalence also varied by region, ranging from $21.4 \%$ in the Pacific region to $34.5 \%$ in the East South Central region. The prevalence of MCC was higher among women than among men within certain U.S. regions, and was higher in older persons in all regions. Such findings further the research and surveillance objectives stated in the U.S. Department of Health and Human Services (HHS) publication, Multiple Chronic Conditions: A Strategic Framework (1). Furthermore, geographic disparities in MCC prevalence can inform state-level surveillance programs and groups targeting service delivery or allocating resources for MCC prevention activities.

NHIS is a multistage health survey of the U.S. civilian, noninstitutionalized population conducted continuously throughout the year. Data on chronic conditions were collected in the NHIS Sample Adult Core questionnaire, in which a sample adult (the respondent) is randomly selected from among all adults aged $\geq 18$ years in the family (a proxy respondent is used if a health condition precludes self-reporting by the sample adult). The final response rate for the 2014 NHIS Sample Adult Core questionnaire was $58.9 \%$ and included 36,697 adults. ${ }^{*}$ Adults who reported a diagnosis of two or more of the following selected conditions were categorized as having MCC: arthritis, asthma, cancer, chronic obstructive

\footnotetext{
*Details on NHIS and its methodology are available at ftp://ftp.cdc.gov/pub/ Health_Statistics/NCHS/Dataset_Documentation/NHIS/2014/srvydesc.pdf.
}

pulmonary disease (COPD), coronary heart disease, diabetes, hepatitis, hypertension, stroke, or weak or failing kidneys. ${ }^{\dagger}$ These conditions were selected to ensure an approach to measuring MCC consistent with previous research using NHIS data (2), and have been included in a condition list developed by HHS (7). Estimates were generated for 50 U.S. states and the District of Columbia, and nine U.S. regions. $\$$ Crude estimates are presented, as they are useful for projecting resource and service delivery needs among adults, an important focus in the HHS MCC strategic framework (1) and in ongoing research on $\mathrm{MCC}(5,6)$. In addition to overall estimates, regional prevalence estimates were also calculated by sex and age. All estimates meet National Center for Health Statistics standard of reliability, 9 and all state denominators had a nominal sample size of $\geq 250$ persons, unless otherwise noted. For all estimates, sampling weights were used; analyses were conducted using SUDAAN 11.0 software to account for the complex sample design. Additional adjustments were

\footnotetext{
$\dagger^{\dagger}$ Diagnosis of arthritis, cancer, coronary heart disease, diabetes, hepatitis, hypertension, and stroke was based on an affirmative response to the survey question "Have you ever been told by a doctor or other health professional that you had... [condition]?" Diagnosis of weak or failing kidneys was based on an affirmative response to the question "During the past 12 months, have you been told by a doctor or other health professional that you had...weak or failing kidneys?" Diagnosis of asthma was based on an affirmative response to each of the following two questions: "Have you ever been told by a doctor or other health professional that you had asthma?" and "Do you still have asthma?" Diagnosis of COPD, was based on an affirmative response to at least one of the following questions: "Have you ever been told by a doctor or other health professional that you had...emphysema?"; "Have you ever been told by a doctor or other health professional that you had...chronic obstructive pulmonary disease, also called COPD?"; or "During the past 12 months, have you been told by a doctor or other health professional that you had...chronic bronchitis?"

$\$$ U.S. regions (and the states constituting them) include the following: Pacific (Alaska, California, Hawaii, Oregon, Washington); Mountain (Arizona, Colorado, Idaho, Montana, Nevada, New Mexico, Utah, Wyoming); West North Central (Iowa, Kansas, Minnesota, Missouri, Nebraska, North Dakota, South Dakota); East North Central (Illinois, Indiana, Michigan, Ohio, Wisconsin); West South Central (Arkansas, Louisiana, Oklahoma, Texas); East South Central (Alabama, Kentucky, Mississippi, Tennessee); New England (Connecticut, Maine, Massachusetts, New Hampshire, Rhode Island, Vermont); Middle Atlantic (Delaware, District of Columbia, Maryland, New Jersey, New York, Pennsylvania); and South Atlantic (Florida, Georgia, North Carolina, South Carolina, Virginia, West Virginia). These nine U.S. regions are based on divisions determined by the U.S. Census Bureau (http://www2.census.gov/ $\mathrm{geo} / \mathrm{pdfs} / \mathrm{maps}$-data/maps/reference/us_regdiv.pdf).

- National Center for Health Statistics standard for reliability is that an estimate have a relative standard error $<30.0 \%$, where the relative standard error is calculated by dividing the standard error of an estimate by the estimate itself, then multiplying by 100 .
} 
applied for the measures of variance accompanying all statelevel estimates. ${ }^{* *}$ All presented differences were found to be significant using two-tailed significance tests $(\mathrm{p}<0.05)$. Twotailed significance tests comparing state and regional prevalence to national prevalence were adjusted to account for dependent samples using procedures described elsewhere (8).

One in four (25.7\%) U.S. adults had a diagnosis of MCC (Table 1), and a number of state prevalence estimates differed significantly from the national average. Prevalence estimates of MCC were higher than the national average in 10 states (Kentucky [38.2\%], Alabama [35.8\%], West Virginia [34.6\%)], Mississippi [34.2\%], Montana [33.2\%], New Mexico [32.9\%], Maine [30.9\%], Michigan [30.3\%], Ohio [29.6\%], and Pennsylvania [29.6\%]), and lower than the national average in six states (Colorado [19.0\%], Alaska [19.6\%], California [20.1\%], Wyoming [20.3\%], Minnesota [20.4\%], and New York [21.3\%]) and the District of Columbia (19.2\%) (Table 1) (Figure).

Reported prevalence estimates of MCC in the East South Central (34.5\%) and East North Central (28.4\%) regions were higher than the national average (Table 2). Prevalence

\footnotetext{
** Taylor series linearization was used for estimation of standard errors for the 10 U.S. states with the largest sample sizes (California, Florida, Georgia, Illinois, Michigan, New York, North Carolina, Ohio, Pennsylvania, and Texas). For the remaining 40 U.S. states and the District of Columbia, the standard error was calculated by multiplying the square root of the average design effect based on the 10 states with the largest sample sizes and the standard error of the estimated percentages under a simple random sample. The $95 \%$ confidence intervals for each state were derived by multiplying this standard error with 1.96 , and subtracting/adding this value to the estimated percentage.
}

FIGURE. Prevalence of diagnosed multiple chronic conditions among adults aged $\geq 18$ years, by state - National Health Interview Survey, United States, 2014

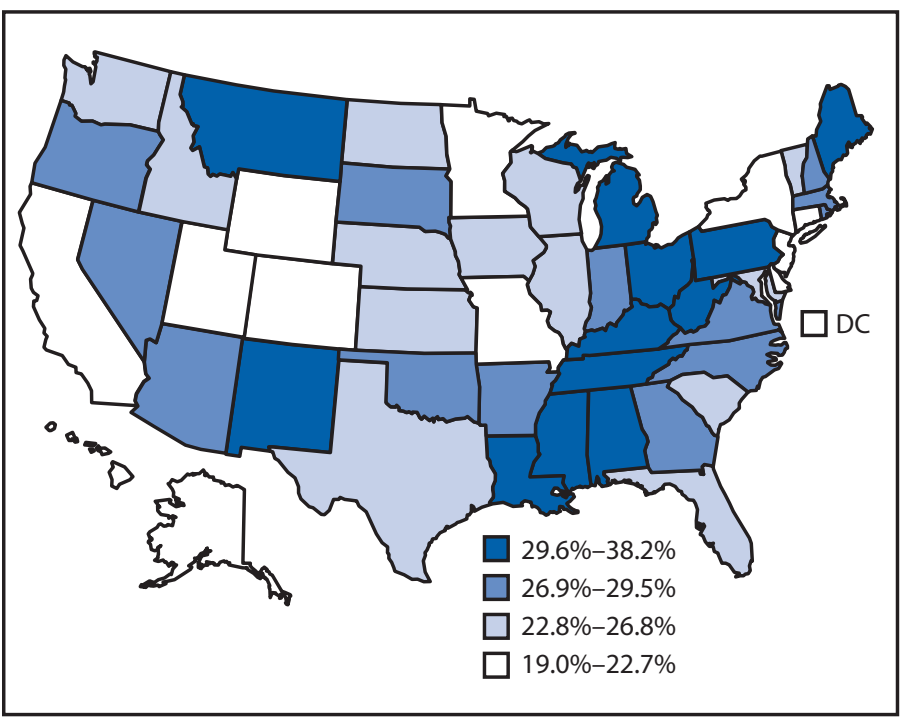

TABLE 1. Prevalence (highest to lowest) of diagnosed multiple chronic conditions* among adults aged $\geq 18$ years, by state or district National Health Interview Survey, United States, 2014

\begin{tabular}{|c|c|}
\hline State/District & $\begin{array}{c}\text { Adults with MMC } \\
\%(95 \% \mathrm{Cl})\end{array}$ \\
\hline Kentucky & $38.2(33.24-43.15)$ \\
\hline Alabama & $35.8(29.93-41.69)$ \\
\hline West Virginia & $34.6(29.44-39.75)$ \\
\hline Mississippi & $34.2(28.95-39.42)$ \\
\hline Montana & $33.2(27.40-38.93)$ \\
\hline New Mexico & $32.9(27.87-37.98)$ \\
\hline Maine & $30.9(26.11-35.64)$ \\
\hline Tennessee & $30.4(25.31-35.54)$ \\
\hline Michigan & $30.3(26.04-34.55)$ \\
\hline Louisiana & $29.8(24.85-34.76)$ \\
\hline Ohio & $29.6(26.18-32.97)$ \\
\hline Pennsylvania & $29.6(25.97-33.26)$ \\
\hline Oregon & $29.5(24.49-34.56)$ \\
\hline Virginia & $29.1(24.67-33.56)$ \\
\hline Oklahoma & $28.9(24.22-33.47)$ \\
\hline Georgia & $28.0(24.92-31.15)$ \\
\hline Massachusetts & $28.0(22.73-33.32)$ \\
\hline Arizona & $27.9(22.84-32.91)$ \\
\hline North Carolina & $27.8(23.84-31.65)$ \\
\hline Arkansas & $27.6(22.36-32.87)$ \\
\hline Indiana & $27.6(22.88-32.25)$ \\
\hline Nevada & $27.6(22.77-32.34)$ \\
\hline New Hampshire & $27.6(22.80-32.29)$ \\
\hline South Dakota & $27.2(22.32-32.12)$ \\
\hline Rhode Island & $26.9(21.47-32.25)$ \\
\hline Illinois & $26.8(22.92-30.69)$ \\
\hline Kansas & $26.6(22.19-30.90)$ \\
\hline lowa & $26.5(21.95-31.00)$ \\
\hline Washington & $26.4(21.93-30.82)$ \\
\hline Texas & $25.6(23.45-27.68)$ \\
\hline Nebraska & $25.5(21.01-30.02)$ \\
\hline North Dakota & $25.5(20.43-30.50)$ \\
\hline Vermont & $25.5(19.86-31.15)$ \\
\hline Wisconsin & $25.4(20.42-30.37)$ \\
\hline Florida & $24.4(20.89-27.86)$ \\
\hline South Carolina & $23.5(18.62-28.31)$ \\
\hline Idaho & $23.3(18.42-28.07)$ \\
\hline Maryland & $22.8(17.86-27.63)$ \\
\hline Missouri & $22.7(17.90-27.43)$ \\
\hline New Jersey & $22.6(18.31-26.90)$ \\
\hline Utah & $22.6(18.33-26.84)$ \\
\hline Connecticut & $22.2(17.12-27.31)$ \\
\hline Delaware & $21.8(17.03-26.56)$ \\
\hline Hawaii & $21.8(16.95-26.72)$ \\
\hline New York & $21.3(18.64-23.93)$ \\
\hline Minnesota & $20.4(16.02-24.69)$ \\
\hline Wyoming & $20.3(15.84-24.77)$ \\
\hline California & 20.1 (18.44-21.69) \\
\hline Alaska & $19.6(15.08-24.01)$ \\
\hline District of Columbia & $19.2(15.00-23.35)$ \\
\hline Colorado & $19.0(14.81-23.24)$ \\
\hline
\end{tabular}

Abbreviations: $\mathrm{Cl}=$ confidence interval; $\mathrm{MCC}=$ multiple chronic conditions.

* Adults with diagnoses of MCC are persons who had been told by a health care professional that they had two or more of the following 10 conditions: arthritis; asthma (current); cancer; chronic obstructive pulmonary disease which includes emphysema (ever), chronic obstructive pulmonary disease (ever), or chronic bronchitis (past 12 months); coronary heart disease; diabetes; hepatitis (ever); hypertension; stroke; or weak/failing kidneys (past 12 months). 
TABLE 2. Prevalence of diagnosed multiple chronic conditions* among adults aged $\geq 18$ years, by region, sex, and age - National Health Interview Survey, United States, 2014

\begin{tabular}{|c|c|c|c|c|c|c|}
\hline \multirow[b]{3}{*}{ Region } & \multicolumn{6}{|c|}{ Adults with diagnoses of $\mathrm{MCC} \%(95 \% \mathrm{Cl})$} \\
\hline & \multirow[b]{2}{*}{ Total } & \multicolumn{2}{|c|}{ Sex } & \multicolumn{3}{|c|}{ Age (yrs) } \\
\hline & & Male & Female & $18-44$ & $45-64$ & $\geq 65$ \\
\hline United States & $25.7(25.08-26.42)$ & $24.1(23.24-25.06)$ & $27.2(26.36-28.13)$ & $7.3(6.72-7.84)$ & $32.1(30.91-33.27)$ & $61.6(60.14-63.11)$ \\
\hline East North Central & $28.4(26.53-30.35)$ & $25.3(22.92-27.80)$ & $31.4(28.90-34.00)$ & $9.1(7.38-11.09)$ & $34.5(31.40-37.64)$ & $65.8(61.50-69.77)$ \\
\hline East South Central & $34.5(31.89-37.16)$ & $32.3(28.50-36.35)$ & $36.3(33.14-39.63)$ & $10.0(7.82-12.77)$ & $45.3(40.21-50.42)$ & $72.3(67.15-76.84)$ \\
\hline Middle Atlantic & $24.1(22.43-25.85)$ & $24.1(21.75-26.54)$ & $24.1(21.93-26.49)$ & $6.5(5.19-8.17)$ & $27.0(24.20-29.95)$ & $58.1(53.94-62.19)$ \\
\hline Mountain & $24.9(22.40-27.54)$ & 21.5 (18.78-24.59) & $28.1(24.75-31.64)$ & $6.3(5.02-8.01)$ & $32.6(28.44-37.01)$ & $62.2(57.24-66.86)$ \\
\hline New England & $26.5(23.95-29.14)$ & $23.6(20.03-27.63)$ & $29.0(25.45-32.78)$ & $6.4(3.98-10.09)$ & $29.1(24.90-33.59)$ & $59.6(53.23-65.65)$ \\
\hline Pacific & $21.4(19.94-22.95)$ & 20.9 (18.92-23.04) & $21.9(19.91-24.02)$ & $6.1(5.05-7.26)$ & $27.8(25.10-30.62)$ & $58.6(54.59-62.47)$ \\
\hline South Atlantic & $26.5(24.79-28.37)$ & $24.8(22.43-27.27)$ & $28.1(25.92-30.44)$ & $7.8(6.50-9.22)$ & $31.8(28.99-34.67)$ & $60.8(57.50-64.07)$ \\
\hline West North Central & $23.4(21.16-25.70)$ & $21.2(18.46-24.21)$ & $25.3(22.54-28.26)$ & $5.1(3.64-7.17)$ & $31.7(28.48-35.18)$ & $58.1(53.26-62.70)$ \\
\hline West South Central & $26.4(24.73-28.17)$ & $25.8(23.20-28.52)$ & $27.0(24.75-29.43)$ & $7.7(6.26-9.32)$ & $36.3(32.51-40.26)$ & $63.1(58.63-67.43)$ \\
\hline
\end{tabular}

Abbreviations: $\mathrm{Cl}=$ confidence interval; $\mathrm{MCC}=$ multiple chronic conditions.

* Adults with diagnoses of MCC are persons who had been told by a health care professional that they had two or more of the following 10 conditions: arthritis; asthma (current); cancer; chronic obstructive pulmonary disease which includes emphysema (ever), chronic obstructive pulmonary disease (ever), or chronic bronchitis (past 12 months); coronary heart disease; diabetes; hepatitis (ever); hypertension; stroke; or weak/failing kidneys (past 12 months).

estimates in the Pacific (21.4\%), West North Central (23.4\%), and Middle Atlantic (24.1\%) regions were lower than the national average.

Women had higher prevalence of MCC than did men at the national level (27.2\% versus $24.1 \%$ ), as well as in the Mountain (28.1\% versus $21.5 \%)$, West North Central $(25.3 \%$ versus $21.2 \%$ ), East North Central (31.4\% versus $25.3 \%$ ), and New England (29.0\% versus 23.6\%) regions. Compared with the average prevalence of MCC among U.S. men overall (24.1\%), MCC prevalence was higher among men in the East South Central region (32.3\%), but lower among men who lived in the Pacific (20.9\%), West North Central (21.2\%), and Mountain (21.5\%) regions. Among women, national prevalence of MCC was $27.2 \%$, and was higher among women who lived in the East South Central (36.3\%) and East North Central (31.4\%) regions and lower among women who lived in the Pacific (21.9\%) and Middle Atlantic (24.1\%) regions.

By age group, overall prevalence of MCC was lowest among adults aged $18-44$ years $(7.3 \%)$, intermediate among persons aged 45-64 years $(32.1 \%)$ and highest among persons aged $\geq 65$ years $(61.6 \%)$; this pattern was observed in all nine U.S. regions. In regions where prevalence of MCC was higher than the national average (East North Central and East South Central), the prevalence of MCC for each age group was also higher than the national average in each respective age group (Table 2). However, among regions with prevalence estimates of MCC lower than the national average (Pacific, Middle Atlantic, and West North Central), only the Pacific region prevalence was consistently lower than the national average when stratified by age.

\section{Discussion}

Approximately one in four U.S. adults had a diagnosis of MCC in 2014, which was similar to the prevalence previously reported for 2012 (2). This 2014 prevalence differed by region and by state. Ten states had prevalence estimates higher than the national average. Similar to previous research that found state-level differences among Medicare recipients (5), the findings reported here display differences among U.S. civilian, noninstitutionalized adults aged $\geq 18$ years (regardless of insurance coverage type). Furthermore, a number of states with higher observed MCC prevalence estimates overlap geographically with states with high stroke mortality rates (the so-called "stroke belt," which includes all of Mississippi and parts of Alabama, Arkansas, Florida, Georgia, Kentucky, Louisiana, North Carolina, Ohio, Pennsylvania, South Carolina, Tennessee, Texas, Virginia, and West Virginia) (9), and the "diabetes belt" (which also includes all of Mississippi and parts of Alabama, Arkansas, Florida, Georgia, Kentucky, Louisiana, North Carolina, Ohio, Pennsylvania, South Carolina, Tennessee, Texas, Virginia, and West Virginia), where past research has noted high diabetes prevalence estimates (10). In addition to state-level differences, regional differences also existed. Examination of MCC by sex and age indicated that, for all regions, prevalence of MCC was higher among older persons; however, differences in MCC among men and women were region-specific.

The findings in this report are subject to at least six limitations. First, only 10 of the 20 conditions identified by HHS for inclusion in studies of MCC $(1,8)$ were used for the measure of MCC in this study (NHIS data have not been collected regularly on the remaining 10 conditions). Second, no mental 


\section{Summary}

What is already known on this topic?

One in four adults in the United States has multiple chronic conditions (MCC), defined as having two or more of 10 diagnosed chronic conditions. Care management of MCC presents challenges to both patients and physicians because of the substantial costs of treating more than one condition and the need to move beyond the traditional focus of care strategies on single conditions to coordinated care.

What is added by this report?

In 2014, $25.7 \%$ of U.S. adults had diagnoses of MCC. For 10 states, prevalence was higher than the national average. Adults living in the East North Central and East South Central regions had higher MCC prevalence estimates than the national average; prevalence estimates were lower among persons living in the Middle Atlantic, Pacific, and West North Central regions. Prevalence of MCC increased as age increased. Prevalence of MCC was higher among women than among men for the United States overall and in the East North Central, Mountain, New England, and West North Central regions.

What are the implications for public health practice?

Findings in this study further the research and surveillance objectives stated in the U.S. Department of Health and Human Services publication, Multiple Chronic Conditions: A Strategic Framework. Geographic disparities in MCC prevalence can inform state-level surveillance programs and groups targeting service delivery or allocating resources for MCC prevention activities.

health conditions were included. Thus, prevalence estimates presented might reflect a conservative estimate of MCC prevalence. Third, only physician-diagnosed chronic conditions were included; undiagnosed conditions are not collected by NHIS. Fourth, adults in long-term care or congregant facilities were not included in the NHIS sample design and therefore were excluded from this study. This limits the generalizability of results to the noninstitutionalized U.S. population. Fifth, crude estimates of MCC are presented for the U.S. states and the District of Columbia. This allowed for identification of states with higher prevalence of MCC, which might be useful in targeting service delivery and projecting resources $(5,6)$; however, comparisons of these estimates with the national average do not account for different age distributions among the 50 states or District of Columbia. Finally, although survey weights are adjusted after data collection to ensure national generalizability, the 2014 NHIS Sample Adult Core response rate could signal nonresponse bias.

A stable national MCC prevalence indicates that diagnoses of MCC continue to be a public health issue. Through Multiple Chronic Conditions: A Strategic Framework (1), HHS has established objectives for addressing this issue. Similar to previous research that found geographic disparities in prevalence of MCC $(5,6)$, this study provides state and regional estimates that can be used to understand which areas of the country have the highest adult prevalence of MCC.

${ }^{1}$ Division of Health Interview Statistics, National Center for Health Statistics.

Corresponding author: Brian Ward, bwward@cdc.gov, 301-458-4568.

\section{References}

1. US Department of Health and Human Services. Multiple chronic conditions-a strategic framework. Optimum health and quality of life for individuals with multiple chronic conditions. Washington, DC: US Department of Health and Human Services; 2010. http://www.hhs.gov/ sites/default/files/ash/initiatives/mcc/mcc_framework.pdf

2. Ward BW, Schiller JS, Goodman RA. Multiple chronic conditions among US adults: a 2012 update. Prev Chronic Dis 2014;11:E62. http://dx.doi. org $/ 10.5888 /$ pcd 11.130389

3. Lehnert T, Heider D, Leicht H, et al. Review: health care utilization and costs of elderly persons with multiple chronic conditions. Med Care Res Rev 2011;68:387-420. http://dx.doi.org/10.1177/1077558711399580

4. Vogeli C, Shields AE, Lee TA, et al. Multiple chronic conditions: prevalence, health consequences, and implications for quality, care management, and costs. J Gen Intern Med 2007;22(Suppl 3):391-5. http://dx.doi.org/10.1007/s11606-007-0322-1

5. Lochner KA, Goodman RA, Posner S, Parekh A. Multiple chronic conditions among Medicare beneficiaries: state-level variations in prevalence, utilization, and cost, 2011. Medicare Medicaid Res Rev 2013;3:E1-19. http://dx.doi.org/10.5600/mmrr.003.03.b02

6. Posner SF, Goodman RA. Multimorbidity at the local level: implications and research directions. Mayo Clin Proc 2014;89:1321-3. http://dx.doi. org/10.1016/j.mayocp.2014.08.007

7. Goodman RA, Posner SF, Huang ES, Parekh AK, Koh HK. Defining and measuring chronic conditions: imperatives for research, policy, program, and practice. Prev Chronic Dis 2013;10:E66. http://dx.doi. org/10.5888/pcd10.120239

8. Cohen RA, Makuc DM. State, regional, and national estimates of health insurance coverage for people under 65 years of age: National Health Interview Survey, 2004-2006. Natl Health Stat Report 2008;1:1-23.

9. Borhani NO. Changes and geographic distribution of mortality from cerebrovascular disease. Am J Public Health Nations Health 1965;55:673-81. http://dx.doi.org/10.2105/AJPH.55.5.673

10. Barker LE, Kirtland KA, Gregg EW, Geiss LS, Thompson TJ. Geographic distribution of diagnosed diabetes in the U.S.: a diabetes belt. Am J Prev Med 2011;40:434-9. http://dx.doi.org/10.1016/j.amepre.2010.12.019 